\title{
DISCURSIVIDADES PRÊT-À-PORTER, FUNCIONAMENTO DE FAKE NEWS E PROCESSOS DE IDENTIFICAÇÃO'
}

\author{
BETHANIA MARIANI ${ }^{2}$ \\ Universidade Federal Fluminense, Instituto de Letras \\ Programa de Pós-graduação em Estudos da Linguagem \\ R. Prof. Marcos Waldemar de Freitas Reis, $s / n^{\circ}$. \\ Campus do Gragoatá, Bloco C, Sala 518. Niterói, RJ, Brasil - 24210-201
}

bmarianidid.uff.br

\begin{abstract}
Resumo. $O$ objetivo deste artigo é discutir o modo de funcionamento do que usualmente tem sido chamado de fake news, tendo em vista as reflexões em torno da pós-verdade. A partir do ponto de vista da análise do discurso, pretende-se a pensar na formação dos laços sociais entre sujeitos que não necessariamente se conhecem, mas que vão sendo instados a tomar posição a partir de demandas feitas por instâncias que disputam o poder valendo-se de pequenos vídeos e palavras de ordem que colocam em circulação as chamadas fake news, que se multiplicam velozmente nas mídias digitais.
\end{abstract}

Palavras-chave: análise do discurso; laço social; processos de identificação; meio digital; fake news.

\begin{abstract}
The purpose of this article is to discuss how the currently coined fake news has been used in light of the reflections made about post-truth. Stemming from the point of view of discourse analysis, we intend to think about the establishment of social bonds between subjects that do not necessarily know one another, but are being urged to take a position based on the demands made by instances that fight for power. Those disputes are materialized by means of short videos and slogans that put in circulation the so-called fake news, which rapidly go viral in digital media.
\end{abstract}

Keywords: discourse analysis; social ties; identification processes; digital media; fake news.

¿El 4 es 4 para todos? ¿Son todos los sietes iguales? ¿Cuándo el preso piensa en la luz es la misma que te ilumina?

(Pablo Neruda, El libro de las preguntas)

\footnotetext{
${ }^{1}$ Este texto foi escrito originalmente para ser apresentado no XI Workshop do Grupo de Pesquisa e Estudos em Linguagem e Subjetividade (GELS), coordenado por Carmen Agustini, na Universidade Federal de Uberlândia. $\mathrm{O}$ título inicial do artigo em tela foi repensado para a presente publicação.

2 Doutora em Linguística pela Unicamp. Docente da Universidade Federal Fluminense, onde atua na graduação e no Programa de Pós-graduação em Estudos da Linguagem. Pesquisadora do Laboratório Arquivos do Sujeito (LAS/UFF). Bolsista de Produtividade em Pesquisa do CNPq.
} 


\section{PALAVRAS INTRODUTÓRIAS}

O título do XI Workshop do Grupo de Pesquisa e Estudos em Linguagem e Subjetividade coloca em cena os termos em torno dos quais uma pergunta é formulada: linguagem e interpretação: (im)pertinências da noção de (pós-)verdade? Eu não sabia, porém, que o título do evento estava formulado sob a forma de uma pergunta ao enviar o título de minha própria participação: discursividades prêt-à-porter e em farrapos: como ouvir e ler? No e-mail em que enviei o título, meio brincando, meio à vera, disse para minha interlocutora: "essa minha pergunta não supõe uma resposta!" E disse isso justamente porque, se algumas perguntas são meramente retóricas, sobretudo em textos acadêmicos, a pergunta em questão resulta de dúvidas que surgiram a partir do momento em que comecei a constituir um corpus a fim de propor um dispositivo de análise para discutir, discursivamente, a tal da pós-verdade e as fake news.

\section{DO FUNCIONAMENTO}

Há um lugar que venho tentando construir e sustentar teoricamente com a análise do discurso tendo em vista a psicanálise. O que é possível reterritorializar discursivamente a partir das indicações que Pêcheux faz em relação à psicanálise? Vale o esforço em levar adiante tal empreitada?

O que tem me interessado é a presença do inconsciente na constituição e na dissolução dos laços sociais, por isso tenho trabalhado com o testemunho. A temática do XI GELS, por sua vez, me impulsionou a pensar na formação dos laços sociais entre sujeitos que não necessariamente se conhecem, mas que vão sendo instados a tomar posição e formar laços a partir de demandas feitas por instâncias que disputam o poder valendo-se de pequenos vídeos e palavras de ordem que surgem, circulam e se multiplicam velozmente nas mídias digitais.

Esses pequenos vídeos, imagens, textos multiplicam-se de uma forma prêt-aporter, ou seja, estão prontos para serem vistos, lidos, espalhados e repetidos como certezas sobre algum caos que vai se instalar, sobre lembranças e alegrias, sobre inseguranças e avisos. Chamo essas materialidades discursivas de prêt-à-porter, ou seja, prontas para o uso e consumo. Em outras palavras, vídeos e textos a serem consumidos velozmente, supondo justamente uma fast-leitura, um passar de olhos. Assim, multiplicam-se piadas e ironias, charges... sobre o cotidiano, o passado, o futuro... sobre algum(a) personalidade, ou para colocar em evidência um anônimo que da noite para o dia pôde se tornar célebre simplesmente porque o sinal de curtir do facebook ou do youtube impulsionou a sua postagem.

Esses textos, imagens ou vídeos são usualmente chamados de mensagens na prática discursiva corriqueira de quem usa a rede digital com todos os termos em língua inglesa que propositalmente utilizei no parágrafo anterior. "Mensagem" é um termo, aliás, bastante adequado uma vez que tais vídeos e textos já se constituíram imersos nos efeitos de evidência, de transparência e de sentido único. Muitas são enviadas por parentes e amigos próximos, com propósitos variados: de um gesto de preocupação à vontade de compartilhar um sentido que supõem de interesse comum. São mensagens em sua maioria anônimas, sem autoria identificada ou identificável. 
Algumas, como estas abaixo, recebi via zap, em momentos diferentes no período de aproximadamente um mês.

(1) "Repassando o alerta. Pessoal, viralizem essa informação para evitarmos que mais pessoas passem pelo mesmo susto que passamos hoje no metrô do Rio. [...]"

(2) "Oi, gente, estou mandando aqui um áudio sem nome, pra todo mundo, estou dirigindo, estamos aqui em Minas Gerais, eu e a Andréia, divisa com a Bahia, eu não vou conseguir descarregar o caminhão antes de segunda, e já estamos avisados, a greve vai voltar..."

(3) "Urgente: Um comboio da $61^{\circ}$ Batalhão de Infantaria de Selva está se deslocando em direção à Base de Santa Maria [...] Segundo fontes que não irei revelar por questão de segurança, general Villas Boas está na região Sul e chamou General de área Mourão Filho e usou a seguinte expressão: Não dá mais, a paciência acabou e chegamos no limite"!! Então pessoal repasse essa informação..."

(4) "A rede Globo tá atrapalhada com as declarações do Faustão, que retratam a realidade do Brasil. [...] Cabe a você perpetuar as declarações dele..."

Dentre as muitas mensagens que recebo, estas foram enviadas por parentes e colegas altamente politizados e críticos. São repassadas no funcionamento prêt-à-porter: aparecem em geral sem uma autoria, e mesmo quando a autoria vem explicitada, trata-se do nome de um blog ou site de notícias. Há uma indeterminação inicial que traz como marca um "repassando", um "para todo mundo", ou um imperativo "repasse", "cabe a você perpetuar". Tais discursividades constroem dessa forma um processo de circulação de sentidos que inclui de forma automática quem enviou como já tendo aderido à tal suposta verdade, e como interpelado de quem a recebeu para que adira também repassando-a automaticamente na maioria das vezes. Em outras palavras, interpelando quem a recebe a aderir para interpelar um outro e assim por diante. São em sua maioria textos anônimos que se dirigem a um "pessoal" indistinto e que vão constituindo uma rede discursiva que enlaça sujeitos entre si a perder de vista.

O que estaria em jogo em tal enlaçamento que faz com que, de uma postagem inicial indeterminada - de um texto, imagem, vídeo -, inicie-se uma circulação prêt-aporter que interpela os sujeitos que recebem essas discursividades para que se apropriem subjetivamente delas ao repassá-las? Dizendo de outra forma, se partem de um anonimato inicial essas postagens vão sendo subjetivadas conforme vão sendo recebidas e repassadas por e para sujeitos que supostamente compartilham sentidos. Produz-se uma rede de discursividades que alimenta uma ilusão de consenso. Ainda dizendo de outra maneira: no repassar para uns e não para outros, supõe-se uma aliança, um compartilhamento de sentidos entre sujeitos situados em determinadas formações discursivas.

O sujeito que recebe a mensagem via zap (ou Instagram ou Twitter ou Face), ao repassá-la, estaria não apenas tomando posição identificado pela formação discursiva na qual se inscreve para ser sujeito do que diz (PÊCHEUX, 1975 [1988], p. 214 e ss.), mas também estaria publicizando essa posição. Nesse processo de subjetivação, estão em jogo as formações imaginárias, ou seja, a imagem que o sujeito faz de si, desse outro que lhe enviou o zap e daquele a quem o zap é reenviado são coincidentes ou bem próximas (PÊCHEUX, 1969 e 1988 [1975], p 188³). Nesse funcionamento há, dessa forma, um

\footnotetext{
${ }^{3}$ Como afirma Pêcheux, "se eu estivesse onde você/ele/x se encontra, eu veria e pensaria o que você/ele/x vê e pensa" (PÊCHEUX, 1998 [1975], p. 188).
} 
encadeamento de tomadas de posição que produzem um assujeitamento "livremente consentido", nos termos de Pêcheux, e imaginariamente sustentado.

\section{PEQUENA DIGRESSÃO NECESSÁRIA}

Em texto publicado já faz alguns anos (MARIANI, 2006), analisei colunas de consultório psicanalítico publicadas em jornais e revistas, e formulei o que chamei de palavras prêt-à-porter. A análise mostrou que, em tais colunas, essas palavras prêt-àporter funcionavam de maneira a sustentar uma imaginária e idealizada individualidade, conformada de acordo com uma pretendida unidade moral vigente. Embora os missivistas escrevessem porque se percebiam divididos (em seus casamentos, em sua sexualidade, em sua profissão, em suas amizades etc.), alguns colunistas, em resposta, davam soluções à moda de manuais de autoajuda, produzindo como efeito tanto uma (suposta) domesticação da divisão subjetiva quanto um possível silenciamento das contradições. Tomando os missivistas de forma individualizada, nessas colunas se construía um processo de produção de sentidos - nessas palavras prêt-à-porter - em que o aconselhamento individual poderia servir (em termos pragmáticos) como modelo não apenas para o missivista, mas também para outros leitores tendo em vista condutas e relações sociais baseadas em uma memória de moral (no sentido kantiano) regulada pelo juridismo (LAGAZZI, 1988). Em outras palavras, o interdiscurso dá sustentação à posição de autoridade do colunista que retoma, formula e põe em circulação, via coluna de consultório, palavras e expressões situadas em uma formação discursiva que se constitui em dada formação ideológica. Dessa posição, o colunista responde a questão de um missivista, ao mesmo tempo em que está sendo lido, também, por um conjunto indeterminado de outros leitores. Ao intervir com sua resposta inserida na memória social, o colunista inscreve o missivista em um processo de identificação a um determinado modelo prêt-à-porter de estar, pensar, relacionar-se e falar a partir de uma evidência de sentidos que lhe é fornecida, em um enlaçamento coletivo pouco crítico e sem resistências.

No reenvio dos zaps, Instagram e Facebook, por outro lado, o funcionamento prêt$\grave{a}$-porter se organiza de outra maneira. $\mathrm{O}$ zap não parte da dúvida (angústia ou sofrimento) de alguém que demanda ajuda a um outro, mas se inscreve no jogo das formações imaginárias supondo que, no cotidiano, as incertezas são várias, e investindo na tentativa de produzir uma adesão a determinados sentidos para aqueles que estariam indignados ou pouco precavidos ou indiferentes ou precisando ser avisados, em suma, aqueles que precisariam saber de X. No processo de circulação desse tipo de discursividade, considerando seu anonimato inicial, vai se produzindo um automatismo no reenvio sobre o que pensar, como se relacionar e o que falar na forma de alertas, de aconselhamentos, de denúncias etc. Em geral, não há uma autoria naquilo que foi postado, não se depreende um enunciador inscrito em uma posição de autoridade, mas o zap vai sendo subjetivado à medida em que é repassado por determinados sujeitos inscritos no jogo das formações imaginárias descrito acima. Assim, o efeito de autoridade e o efeito de verdade do que está sendo dito e repassado se produz a partir daquele que, ao receber, reenvia a postagem, ou seja, a sustentação do dizer funciona horizontalmente na rede familiar ou de amigos ou de colegas de trabalho que se encontra na agenda de telefones ou no grupo de amigos do Face e/ou Instagram.

Apesar dos dois modos de funcionamento não se realizarem da mesma forma, as discursividades prê-à-porter têm sua eficácia ao colocar em circulação determinados 
sentidos que podem produzir aderência, ou seja, um colamento a determinados sentidos já sob efeito de evidência.

\section{UMA PALAVRINHA...: MÍDIA IMPRESSA, ZAPS E CIRCULAÇÃO DE FAKE NEWS, OU... FAUSSE NOUVELLES}

Quando veio o convite para participar do XI GELS, ainda em 2017, coloquei como ponto de partida perguntar se essas discursividades e sua circulação eram notícia para a mídia impressa. Assim sendo, me dispus, durante aproximadamente três ou quatro meses, a recortar e ler de forma não exaustiva, e não sistemática, o que era publicado em dois jornais que leio usualmente, O Globo e Folha de São Paulo. Como gesto inicial de leitura, trouxe de volta o que defendi em 1996 (MARIANI, 1998): a mídia impressa, ao pautar o que vai e o que não vai ser notícia, agenda um domínio de pensamento, ou seja, agenda o que seus leitores podem e devem pensar durante a semana. Tanto $O$ Globo quanto a Folha de São Paulo são jornais que fazem parte da grande imprensa, atendendo a interesses financeiros e publicitários de empresários e políticos bem como de grandes corporações nacionais e internacionais. Conforme já foi discutido em outro momento (MARIANI, 1996), a grande imprensa funciona de modo a agendar domínios de pensamento para seus leitores. Com essa breve recolha visando a constituição de um corpus discursivo, foi possível observar que, pelo menos nesses dois jornais mencionados, há espaço para agendar o que seus leitores podem e devem pensar sobre a sociedade cada vez mais digitalizada e submetida aos zaps, instagrans e similares. Se o discurso jornalístico impresso toma como notícia a circulação das notícias em rede digital, o que estaria em jogo nessa agenda brasileira? De que forma o jornalismo impresso intervém na formação dos laços sociais, nos processos de identificação?

Apresento algumas dessas matérias sobre as mídias digitais que, de forma didática, como convém ao discurso jornalístico em seu efeito de agendar o que se deve pensar, foram publicadas entre dezembro de 2017 e abril de $2018^{4}$.

(5) "Epidemia de fake news. [...] o problema só vai piorar se as pessoas só lerem os meios que refletem a sua opinião" ( $O$ Globo, primeiro caderno, p. 17, 25/12/2017);

(6) "As redes sociais e a democracia", por Cora Rónai, em 30/01/2018, e "O apocalipse da informação", por Clóvis Rossi, (FSP, p. A16, 04/03/2018);

(7) Le Monde: "Facebook, j'accuse!" (FSP, p. A6, 11/02/2018);

(8) "Será que as redes sociais estão substituindo os intelectuais?" (FSP, Caderno Ilustríssima, 18/02/2018);

(9) "Foi correta a decisão da Folha de deixar o Facebook? SIM. Uma atitude exemplar" (FSP, p. A3, 24/02/2018);

(10) O que são "fake vídeos" (FSP, p. A30, 10/03/2018);

(11) "Norman, o robô psicopata, experimento do MIT que cria máquina educada nos piores fóruns de discussão da internet" ( $O$ Globo, 15/04/2018).

Depreende-se de imediato o uso da terminologia atualizada pela língua inglesa: fake news, mas não fausse nouvelles, por exemplo. E tal denominação ou já aparece como pré-construído, como algo já sabido, como em (5), ou que precisa ser sabido, como em

\footnotetext{
${ }^{4}$ No momento em que envio esse artigo para publicação, os jornais Folha de São Paulo e O Globo abriram páginas inteiras dedicadas a desfazer boatos, visando desdizer fake news.
} 
(10 e 11). Além disso, como se pode observar em (6), o tema não se encontra explorado apenas nas matérias, os colunistas especializados em mídia digital promovem também discussões sobre o mau uso das redes sociais. Outro aspecto é a reprodução de denúncias feitas em jornais estrangeiros considerados sérios, como o Le Monde. Ou ainda, como em (9), publicar de forma elogiosa em seus editoriais seus próprios posicionamentos diante das mídias sociais.

É importante observar que, ao nomear como fake notícias e vídeos que não corresponderiam exatamente ao que os jornais, em sua ideologia de neutralidade e objetividade, consideram como fatos objetivos, o discurso jornalístico impresso estabelece de um outro lado a existência de truth, da possibilidade de descrição objetiva dos tais fatos, e se inscreve auto-referencialmente, portanto, como lugar do discurso da seriedade (ORLANDI, 1983). Mas, sabemos que toda a dita realidade é construída pela linguagem em sua relação com a historicidade e submetida ao funcionamento ideológico, logo, o discurso jornalístico impresso, ao discutir a mídia digital, busca significar-se como menos submetido ao funcionamento das fausses nouvelles.

Voltando à questão formulada.... Embora muitos de vocês possam estar vislumbrando uma possível resposta para a pergunta "o que está em jogo nessa agenda do discurso jornalístico impresso", sobretudo neste período pré-eleitoral, vale retomar Pedro Doria, economista, autor de uma coluna no jornal $O$ Globo e produtor de um site de notícias chamado Meio. Doria, assim como Cora Rónai e Clóvis Rossi, dentre outros colunistas, dedicou uma de suas colunas à agenda em curso. Ele recentemente escreveu que "há, nas entranhas do WhatsApp, um outro Brasil" (DORIA, O Globo, primeiro caderno, p. 21, 01/06/18). Pensemos que somos mais de 207 milhões de habitantes (IBGE, 2017) e que há 120 milhões de pessoas inscritas nesses tipos de mídia digital, número que pode ser reduplicado, pois muitos de nós não pertencemos apenas a uma rede.

De forma detalhada, Doria explica a organização das mensagens nos "grupos de notícias" (DORIA, idem). De seu ponto de vista, em grupos de zaps que não podem ter mais do que 256 membros, de um lado há uma "estrutura de marketing político de guerrilha em formação fazendo um jogo sujíssimo", e, simultaneamente, do outro lado, se encontra "um novo tipo de brasileiro, despolitizado e, no entanto, engajado, tentando compreender a confusa realidade à volta, com as poucas ferramentas de que dispõe" (DORIA, idem).

Esses grupos de zap não funcionam como nossos grupos, mas o que acontece é que muitas vezes recebemos textos (falados, escritos, imagéticos) desses grupos de notícias em nossos zaps familiares, de amigos ou de trabalho porque alguém que conhece alguém... que está em um desses grupos, os quais, em sua grande maioria, são de extremadireita. Doria diz que o marketing político organizado nesses grupos se alimenta com duas informações cruciais. A cada novo inscrito, segue-se seu telefone com o DDD, o que permite um mapeamento dos interessados naquele tipo de discursividade. Além disso, cada inscrito representa um lugar de interesse, um lugar a ser preenchido com sentidos produzidos pelo grupo.

Durante a greve de caminhoneiros, por exemplo, houve um incremento notável na circulação de notícias bombásticas sobre uma possível escassez total de alimentos, de golpe militar, de massas convocadas para irem às ruas e assim por diante. Os quatro zaps que enumerei anteriormente circularam exatamente nesse período. Nos zaps de áudio, por exemplo, eram teatralizadas vozes de homens com sotaque do interior de São Paulo ou 
de Minas Gerais, todos serenamente dizendo que a greve não iria acabar, que a população iria presenciar um caos social.

No modo de produção dos processos de sentido, depreendemos a ficcionalização de uma espontaneidade (sobretudo como em (2), em que há a ancoragem enunciativa de um eu/aqui/agora assumindo a enunciação), com charges e reprodução de diálogos simulados, ou a construção de efeito de seriedade com a divulgação de dados supostamente científicos ou sigilosos. Nesses grupos, há os que se dedicam apenas à produção de sentidos, ou seja, à elaboração de material novo a ser distribuído para entrar em circulação incessante e há, também, os outros que colocam as discursividades em circulação, ou seja, alimentam incessantemente os grupos com novos memes e postagens.

No que me diz respeito, por exemplo, recebi um vídeo que registrava uma gráfica imprimindo de forma contínua o enunciado "intervenção militar já" ( $c f$. anexo 1) e, sem refletir muito, mas já subjetivando esse vídeo, repassei o dito cujo vídeo para vários grupos de amigos e familiares. Não saberia refazer o longo encadeamento de reenvios até que o vídeo chegou em meu zap particular! Mas a questão é que, ao reenviá-lo, tomei aquela produção de sentidos como uma verdade e me inscrevi em uma posição de crença, ou seja, acreditei - tendo em vista a ditadura militar brasileira e a memória recente das manifestações sociais ocorridas desde 2103, quando se viu e ouviu uma demanda de volta dos militares - que aquele vídeo denunciava de fato uma suposta ameaça à democracia.

Esse é um ponto que quero reter para depois retomá-lo: tomei o zap como verdade, logo, vi-me aderida a um efeito de sentido, e isso foi possível porque de algum modo eu acreditei no que via, lia e ouvia.

A produção discursiva contínua desse marketing político, nesse processo de construção de efeitos de verdade, aqui compreendido de forma simplificada como tentativa de manipulação do outro, como forma de influenciar a opinião pública e (re)direcionar os laços sociais a partir de interesses políticos, não é de hoje. As fausses nouvelles ou fake news estão na ordem do dia associadas ao que se chama de pós-verdade. Sinteticamente, o que está em jogo poderia ser descrito assim: os grupos políticos hegemônicos, ou que pretendem a hegemonia, trabalham o simbólico para desestabilizálo, ou seja, produzem incansavelmente as discursividades que pretendem impor como sentido supostamente único e verdadeiro nas instituições escolares e religiosas, na mídia e na cultura. O discurso político de marketing a serviço de instâncias de poder constrói ficções a partir de acontecimentos, coloca essas ficções em circulação e as alimenta continuamente, como vimos, visando uma aderência à discursividade prêt-à-porter e um efeito-cola, de adesão, com novos reenvios.

\section{UMA PARADINHA}

Nessa discussão em que até o momento enfatizei o processo de produção de sentidos, outro aspecto a ser colocado são essas noções que vêm sendo dicionarizadas já como conceitos novos, pós-verdade e fausses nouvelles, ou fake news, como um saber sendo produzido. Ora, "desconhece-se a história dos conceitos, ou que os conceitos têm uma história" (ORLANDI, 1983, p. 15). O uso de uma terminologia diferente representaria um novo conceito? 
A chamada pós-verdade dos tempos atuais nada mais seria senão a exacerbação de uma propaganda política polarizada sendo produzida incessantemente para atingir de forma ultrarrápida a sociedade a fim de desestabilizar laços sociais. Com a presença das novas tecnologias digitais, esse marketing é feito de modo ainda mais refinado, de forma a atingir emocionalmente o sujeito: chega em seu celular algo que pode afetar seu equilíbrio, suas certezas cotidianas, sobretudo, com a divulgação de situações apocalípticas, catastróficas.

Vindo do campo da filosofia, Rodrigues, em seu artigo "Posverdad y apocalipsis" , afirma que o termo pós-verdade foi dicionarizado em $2016^{6}$, mas teria sido formulado e utilizado pela primeira vez em 1992 por Steve Tesich, um escritor sérvioamericano. $^{7}$

Em outros tempos históricos, afirma Rodrigues, a fabricação de verdades também estava presente. "Su origen parece remitirse a la Propaganda Fide, del siglo XVII, creada por la Iglesia católica para enfrentar la expansión de las iglesias protestantes y para contenerlas en el Nuevo Mundo" (RODRIGUES, idem). Nos dias de hoje, afirma Rodrigues, "la verdade se convertió en un terreno de luchas de poder...". Para o autor, no campo da filosofia, essa luta seria resultado direto de uma noção construtivista de realidade. Seríamos, nas palavras do autor, fillhos bastardos de Nietzsche: se não há verdades definitivas e a realidade é sempre uma construção, só nos resta lidar com múltiplas perspectivas de verdade. Ou, em outras palavras, com a luta entre múltiplas interpretações. ${ }^{8}$

\section{RETORNANDO...}

Como analistas do discurso, visamos compreender e analisar os processos de produção desses sentidos hegemônicos com a produção de efeitos de verdade, ou seja, os processos de produção dessas interpretações que se produzem como verdadeiras em seus modos de produzir evidências e aderências. Vale aqui retomar a definição de Rossi Landi (1973), tal como Orlandi (1983) ${ }^{9}$ a pensa. Rossi Landi propõe a linguagem como trabalho

\footnotetext{
${ }^{5}$ Roberto Solarte Rodrigues (2018, texto inédito disponível no portal www.academia.edu, consultado em março, 2018).

${ }^{6}$ Dicionário Oxford (2016): “Adjetivo: Hace relación o denota circunstancias en las cuales los hechos objetivos influyen menos en la formación de la opinión publica que la apelación a las emociones y a las creencias personales" (apud RODRIGUES, 2018). E, no Dicionário da Real Academia Espanhola, como "distorsión deliberada de una realidade, que manipula creencia y emociones cone 1 fin de influir en la opinión pública y en atctitudes sociales. Los demagogos son maestros de la posverdade" (ibid., idem).

7 “[...] en el periódico the Nation, afirmo en 1992 que después de los últimos grandes escândalos políticos de la nación estadounidnense (referindo-se, en este orde: al Watergate, la condena de Oliver North y la cobertura de la Guerra del golfo) demonstram que 'Nosostros, como Pueblo libre, hemos decidido libremente que queremos vivir en un mundo post-verdad" (apud RODRIGUES, idem).

8 V. tbm. Richard Martineau: “Qu'est-ce qu'une fausse nouvelle?”, disponível em: http://www.journaldemontreal.com/2018/01/08/quest-ce-quune-fausse-nouvelle.

9 Orlandi (1983, p. 18), discutindo Rossi Landi na perspectiva da AD, afirma: "posso considerar a linguagem como um trabalho. No sentido de que não se tem um caráter nem arbitrário nem natural, mas necessário. E essa necessidade se assenta na homologia que podemos fazer entre linguagem e trabalho, i.e., considerando que ambos são resultados da interação entre homem e realidade natural e social, logo, mediação necessária, produção social. Quando falamos em mediação, gostaríamos de dizer que não pensamos essa mediação no sentido de colocar a linguagem como instrumento, mas pensamos, antes, a mediação como relação constitutiva, ação que modifica, que transforma. [...] O estudo da linguagem não pode, pois, nessa perspectiva que adotamos, estar apartado da sociedade que a produz" (ORLANDI, 1983, p. 18 e 19).
} 
e como mercado, como mediação necessária e constitutiva da relação entre homem e mundo. Assim, discursivamente, podemos compreender que é nesse trabalho da linguagem, que se faz necessariamente entre sujeitos na sociedade e na história, logo, como produção simbólica, que se materializam as violentas tentativas de interferências dos grupos hegemônicos nos processos de produção dos sentidos a fim de impor uma única significação. São muitas as análises discursivas que já foram feitas e vêm sendo feitas sobre os movimentos de resistência frente à política de silenciamento provocada pela censura em muitas e distintas condições de produção, ou sobre os efeitos violentos da colonização e da descolonização linguística... e por aí vai.

Considerando as explicações de Doria sobre a maneira como os grupos de zap são feitos, o funcionamento das discursividades prêt-à-porter corresponde a um desses processos de interferência. Essas discursividades prêt-à-porter fomentam uma produção de efeitos de verdade que vão alimentando as formações discursivas, objetivando produzir uma aderência/não aderência a determinados sentidos. Porém, sabemos que a interpelação ideológica atravessa o processo de produção de evidências, ou seja, por mais que a práxis de uma tal discursividade prêt-à-porter seja sutil ou elaborada na sua produção de efeitos de verdade, o sujeito não necessariamente será capturado pelas redes de sentidos lá discursivizadas. E sabemos também que não há produção de sentidos totalizante, pois, na relação entre linguagem e historicidade, o real se interpõe de forma constitutiva. $O$ real marca um impossível do tudo dizer desde sempre inscrito na ordem de uma língua que falha inexoravelmente, e, porque é estrutural, o real da língua leva o sujeito se equivocar. Em Pêcheux, o equívoco linguístico, esse ponto não localizável e não atingível de impossível que na língua afeta o sujeito, se enlaça à contradição, ponto de real da história, em suas contradições (PÊCHEUX \& GADET,1981, em discussão com Milner, p. 64). Se uma fausse nouvelle pode afetar e desorganizar o mundo semanticamente normalizado de um sujeito, pode também não afetar em nada. Não há garantias.

Se não é de hoje esse tipo de produção de fausses nouvelles com um funcionamento prêt-à-porter, e se não é de hoje que trabalhamos analiticamente com seus processos, o que se altera atualmente são as condições históricas de produção. O que há de diferente está na historicidade do acontecimento do meio digital, que, nas atuais condições de produção, amplifica consideravelmente a circulação das discursividades, atingindo e afetando de forma mais próxima o um-a-um, as condições individuais de existência. Vamos falar um pouco sobre essas condições.

Mas, antes, é preciso lembrar que o que funciona na linguagem funciona no sujeito. Orlandi já afirmou inúmeras vezes que sujeito e sentidos se constituem mutuamente. Também já afirmou que nem os sentidos nem o sujeito coincidem consigo mesmos. Estamos inscritos no jogo das contradições, das identificações e contraidentificações em meio às diferentes formações discursivas.

\section{OUTRA PEQUENA DIGRESSÃO}

Do meu ponto de vista, incorporando e reterritorializando a psicanálise, essa ligação tão "íntima" entre o sujeito e a língua que fala se marca na própria língua materna esquecida, e aqui penso na musicalidade, na sonoridade, no jogo de lalangue que atropela fazendo falhar o léxico, a sintaxe, e deixando o sujeito ser entrevisto no tropeço. Assim, de minha parte, e pensando com a psicanálise, afirmei que, considerando a lógica da temporalidade do só-depois, significantes e sujeito se constituem mutuamente para que 
sentidos possam colar em significantes. Nesse ponto, de que sujeito falo? Do sujeito do inconsciente. Esse sujeito do inconsciente não aparece assim, dado, pronto. Ele é evanescente e pontual, não tem consistência tangível e não se deixa nem aprender nem compreender facilmente. Para falar dele é preciso adentrar cuidadosamente no terreno aberto por Freud e Lacan para se considerar que sujeito (do inconsciente) e significante se constituem e se afanizam no momento em que enxames de significantes dão início (mítico) ao que poderá se constituir, de modo singular, na amarração do nó real/simbólico/imaginário.

Tendo em vista pequenas aberturas de possibilidades de diálogos teóricos que Pêcheux foi formulando em sua obra entre a Análise do Discurso e a Psicanálise, tenho destacado, eventualmente mais a partir de autores da/na Psicanálise do que de Pêcheux, a importância de se considerar um tempo lógico pré-verbal, uma temporalidade em que não há sentidos para aquele que ainda não fala. Há uma massa sonora indistinta, como nos diz Saussure, há musicalidade da voz, enfim, uma sonoridade em torno do berço que significantiza e dá contornos, aos poucos, ao corpo do infans. Essa sonoridade fica como resto, como lalangue, como marca do desejo interditado, marca do que há de singular na constituição do sujeito a partir de uma língua materna particular que é, paradoxalmente, língua materna de todos.

São traços significantes que vão possibilitar (ou não) a formação de uma cadeia significante à qual se entrelaçarão alguns sentidos, não todos. Esse enxame de traços iniciais, como nos diz Lacan, iniciam a cadeia significante ficando excluídos dela, mas produzindo efeitos. A ausência presente dessa marcação inicial não porta sentidos, é um furo (real) em torno do qual simbólico (que insiste) e imaginário (que consiste) formam bordas. Diferentemente de Freud, que pensava ser possível vislumbrar a origem dos sintomas nos retornos dessa ausência se fazendo presente, para Lacan esse furo é o que ele chama de inconsciente real (que ex-iste), totalmente exterior ao sujeito e fora do sentido.

Em Pêcheux, em sua releitura de Freud e Lacan, na práxis discursiva se dá a "ocultação", a palavra ocultação é dele, do funcionamento do pensamento, que é sempre, a partir de Freud, inconsciente (PÊCHEUX, 1988 [1975], p. 175). Para Pêcheux, o que está nesse funcionamento do inconsciente, um funcionamento que se dá a saber, mas que não é sabido, é uma articulação entre representações do sujeito que remetem umas às outras a partir da identificação simbólica. O processo de identificação, que não é sem o imaginário inscrito na identificação, produz como efeito ideológico a ilusão da intersubjetividade e do consenso. É assim que Pêcheux busca explicar o esquecimento número 2 e a adesão do sujeito à determinada formação discursiva que o domina. A identificação simbólica, então, está sujeita às leis da língua - ele dá como exemplo a verneinung freudiana (PÊCHEUX, 1988 [1975], p. 176) - e se encontra em relação com esse imaginário das identificações, "através das quais toda representação verbal, portanto toda 'palavra', 'expressão', ou 'enunciado', se reveste de um sentido próprio, 'absolutamente evidente', que lhe pertence" ${ }^{10}$. Haveria, deste modo, um corpo verbal (imaginário linguístico) propiciando a identificação simbólica.

Anos mais tarde, ainda retomando discursivamente a noção de identificação, Pêcheux dirá “o simbólico entra em uma relação específica com o real e o imaginário,

${ }^{10}$ Isso está dito, de outra forma, também na nota 47, na página 184 (PÊCHEUX, 1988 [1975]). 
determinando a subjetividade como efeito da interpelação de que o sujeito é o lugar, pelo viés da identificação" (PÊCHEUX, 2011 [1982], p. 64).

\section{ADESÃO COMO CRENÇA?}

Nem dividido nem contraditório, mas sim alienado, pouco resistente e acrítico, esse é o eu que se almeja nas relações capitalistas. Com cautela, Freud, em Psicologia das massas e análise do eu (1921), perguntava-se como funcionavam as identificações, garantindo a articulação do $e u$ ao líder que manejava as massas. Se digo que Freud se perguntava com cautela é porque todo psicanalista, em sua prática, se ancora em um saber que não domina, o saber inconsciente.

Se trazemos o questionamento para os dias atuais, podemos nos perguntar como funcionam as identificações nos grupos de zaps, facebooks e intagrams. Já mencionei que, na horizontalidade de suas redes, essas mídias digitais se organizam em torno de uma ausência de autoria e que é no reenvio que elas se subjetivam. Elas são construídas em torno de determinados significantes - greve, atenção, cuidado - e constroem um nós que (se) dá (na) sustentação no um-a-um que alimenta a rede e coloca discursividades prêt-àporter em circulação. Esse modo de funcionamento na horizontalidade se materializa tanto nos zaps e faces individuais quanto naqueles que funcionam em grupos.

Pertenço a grupos de zaps institucionais ("Colegiado Pós-ling”), a zaps de grupos de estudos ("Sobre o saber do psicanalista"; "GT AD"; "LAS"), ao grupo zap de um clube ("Marimbás"), zaps de amigos variados ("Vizinhos", "O discurso que nos uniu") e vários de família ("Família"; "Mariani's"; "Cunhadas"; "Irmãs"). No Facebook, minha rede se estende a conexões com faces aos quais me liguei por identificações variadas: "Bairro do Flamengo e adjacências" e "Bairro das Laranjeiras", em ambos para saber da segurança na região em que moro; "À Esquerda da Praça", para saber das lutas e movimentos de resistência que se realizam na pracinha perto de onde moro; "Diário literário digital"... nem lembro mais o porquê! e outros. E recebo diariamente notícias de faces de propagandas que vendem roupas, comidas, vários que desconheço completamente e que adentram minha página sem que eu saiba exatamente o porquê. Esse processo de organização de grupos zaps e faces não tem limites: podemos fazer tanto quanto quisermos, podemos nos inscrever em tantos quantos quisermos, mas nunca serão quaisquer, pois são por suposta identificação ou necessidade de interesses compartilhados.

Nas palavras de Rivera"1, a circulação de "significantes identitários" baliza a construção de um nós identitário - digamos, um conjuntinho de eus identificados entre si e bastante satisfeitos com suas supostas semelhanças identitárias - que de forma inexorável exclui os outros. Quanto mais esse eu se aliena nos likes e carinhas que inclui a cada momento em que é interpelado pela mídia, o próprio sujeito é excluído (ou não, como veremos a seguir).

O sujeito, na psicanálise, é o que se rebela em relação ao $e u$, ele não coincide com o eu; ele mostra a divisão do eu. Esse sujeitinho está sempre às voltas com enigmas que emergem nos sonhos; com suas risadas inoportunas, quando se espera o choro; com sua angústia quando aparentemente tudo vai bem; com seu tropeço nas palavras mais

11 Rivera, T. disponível em: http://psicanalisedemocracia.com.br/2017/04/a-subversao-do-sujeito-comogesto-politico-por-tania-rivera/. 
corriqueiras. Algo estranho se passa no sujeito, e ao mesmo tempo, esse algo estranho é estranhamente familiar. Em suma, ele fala o que não deve ou não se espera e, assim, mostra inesperadamente sua sintaxe própria, que expressa a gramática do desejo inconsciente. Lacan chama de "subversão do sujeito" isso que produz desestabilização do $e u$, indicando que algo não vai bem nesse teatro individual que se encontraria partilhando um coletivo identitário de "consciências".

O sujeito segundo a psicanálise é aquele que "não é senhor em sua própria casa", no célebre bordão freudiano, e portanto implica, justamente, um movimento de reviramento das construções imaginárias que o estabilizam e aprisionam em formações identitárias que lhe oferecem o pertencimento a uma "casa" que corresponderia a uma dada situação social, em compartilhamento com seus "semelhantes". Isso não significa, porém, que ele esteja condenado a ser aparição efêmera e disruptiva apenas no âmbito íntimo e privado (capaz de se dar, por conseguinte, especialmente na situação clínica clássica (e protegida) do consultório de psicanálise). (RIVERA, idem)

Dessa citação de Rivera, destaco o final, pois ali a autora argumenta que o inconsciente se manifesta não apenas na clínica. No consultório, sem dúvida, a manifestação do inconsciente é crucial no manejo do processo de análise e na direção da cura. Porém, como nos alerta Rivera, o inconsciente "não está condenado a ser aparição efêmera e disruptiva apenas", apenas na privacidade da clínica. Sendo assim, quais efeitos da presença do inconsciente - a singularidade enquanto diferença - nos grupos, ou massas, como diz Freud? Freud, aliás, sobretudo em suas obras Interpretação dos sonhos, O chiste e Psicopatologia da vida cotidiana, apresenta uma coleção de sonhos, chistes e lapsos variados que tanto são seus próprios ou de seus pacientes como também são aqueles relatados por amigos ou lidos em jornais da época. Freud extrai clinicamente as consequências das manifestações do inconsciente em seus pacientes e em si próprio ao mesmo tempo em que tenta compreender a época em que vive incluindo, para tanto, justamente, a presença do inconsciente. Para Rivera,

Esta é, a bem dizer, uma questão central para a psicanálise, e, no entanto, pouco explorada: a potência de subversão do sujeito poderia ser transmitida, no âmbito social? Poderia ser de algum modo compartilhada, como uma centelha de ligação entre nós?” (RIVERA, idem)

A autora que menciona a arte como lugar das pequenas subversões que materializam no social a revolta do sujeito porque a arte está sempre mexendo nas cadeias significantes já estabilizadas. A arte como possibilidade de se fazer algo com o real. Ela se pergunta, então, pelo que se espraia pelas ruas para além da arte. Considerando que há várias maneiras de se fazer arte, e que essas maneiras também se manifestam nas ruas, podemos (nos) incluir na pergunta de Rivera: a afirmação da singularidade, da diferença, no lugar da cristalização imaginária do eu em relação à massa, poderia "agir na contracorrente da alienação identitária da massa como reafirmação do pacto social em outras bases?" (RIVERA, idem).

Nos termos da Análise do Discurso, uma teoria materialista dos processos de produção discursivos (PÊCHEUX, 1988 [1975], p. 131), ou seja, das formas de constituição, formulação e circulação dos sentidos, como sabemos, esse sujeito do inconsciente está incluído na conceituação proposta por Pêcheux (1988 [1975], p. 152) enquanto estrutura-funcionamento. Sujeito preso desde sempre em redes significantes que 
o antecedem e que, por identificação, promovem a adesão a significantes identitários, colocando em jogo o que baliza e fornece sustentação como o espaço-tempo imaginários do eu. Segundo Pêcheux, isso está na base da interpelação ideológica na base do processo significante da interpelação. A consequência do primado do significante sobre o signo e o sentido, diz Pêcheux, é considerar que "o significante toma parte na interpelaçãoidentificação do indivíduo em sujeito" (PÊCHEUX, 1988 [1975], p. 264). Sendo que os processos de identificação, como vimos na seção anterior, estão ligados imaginariamente à evidência do sentido, evidência que se produz em um tempo lógico simultâneo ao da interpelação (PÊCHEUX, idem, p. 265). Mas, os rituais da interpelação ideológica não são totalizantes, nenhum assujeitamento ideológico é completo: a não coincidência entre sujeito e sentidos está nas falhas do ritual.

Há pelo menos um ponto a reter do que Pêcheux afirma em "Só há causa daquilo que falha", ainda visando articular teoricamente o que se manifesta nas falhas.

O lapso e o ato falho (falhas do ritual, bloqueio da ordem ideológica) bem que poderiam ter alguma coisa de muito preciso a ver com esse ponto sempre já aí, essa origem não detectável da resistência e da revolta: formas de aparição fugidia de alguma coisa 'de uma outra ordem', vitórias ínfimas que, no tempo de um relâmpago, colocam em xeque a ideologia dominante tirando partido de seu desequilíbrio. (PÊCHEUX, 1988 [1975], p. 303)

Por outro lado, de alguma forma, o modo como Pêcheux propõe o processo de identificação-interpelação-identificação (e esse processo vai se encadeando, se deslocando e se renovando justamente porque é processo) me ajuda a compreender minha aderência, adesão, sem resistências àquele vídeo que recebi durante a greve dos caminhoneiros.

Quem de nós, que pertencemos a tantos grupos digitais, ainda não tropeçou de forma crédula em alguma postagem apocalíptica ou de frase de autoajuda ou de piadinha tolinha ou de correntes de oração? E quem de nós não reenviou a tal postagem sem pensar muito, certos de um sentido, simplesmente porque teria sido enviada por algum amigo pertencente, assim como nós, a algum grupo de zap ou de face ou de instagram? Os processos de identificação que atuam no pertencimento a grupos produzem efeitos de comunhão a determinados sentidos, ou melhor, da existência de sentidos em comum, discursividades a serem partilhadas. O pertencimento a um ou mais desses grupos confere uma ilusão de segurança, como uma partilha de ideais, de convicções. Ilusão de consenso, de identidades estáveis em comum (a presença de um nós inclusivo-exclusivoexcludente) que produz como efeito a ilusão de uma rede de proteção, de segurança. $O$ que seria da ordem da singularidade, logo, da diferença, por efeito da ilusão de pertencimento, pode produzir a ilusão do grupo coeso, homogêneo, do sentido único.

Toda essa explicação, porém, ainda não me parece suficiente para ajudar na compreensão do que está em jogo no momento em que recebemos e, aderindo, tomamos como verdade o que foi enviado.

\section{AS CRENÇAS...}

Lembro de uma longínqua aula de filosofia, no primeiro ano da faculdade de Letras, em uma universidade católica, quando a professora perguntou para a turma o que 
era fé. Após inúmeras respostas, em sua maioria ligadas ao aspecto religioso, a filósofa nos disse que a fé, compreendida como ter confiança no outro, estava em nosso cotidiano, em nossos pequenos atos diários, como, por exemplo, pegar o elevador para chegar em algum andar sem ficar pensando que ele poderia cair. A fé estaria nas experiências do cotidiano, o tal mundo semanticamente estabilizado e pragmaticamente organizado. Essa ideia de fé é o que impregna e que constrói as convicções, a capacidade de acreditar (na boa fé) do outro.

Quais os sentidos de crença? Benveniste (1995), em suas pesquisas sobre o "acontecimento global" que foi o indo-europeu, em seus estudos sobre as "migrações e implantações" que o parentesco linguístico fabricou em línguas distintas, relaciona crédito, crença e autoridade. O termo latino 'crêdô' ("confiar uma coisa com certeza de recuperá-la") deriva de uma forma antiga no Veda que significava "ato de confiança (num deus) implicando retribuição (sob a forma de favor divino concedido ao fiel)" (BENVENISTE, 1995, p. 171). Para o autor, aí se encontra "o fundamento da noção laicizada de crédito, confiança, qualquer que seja a coisa fiada ou confiada" (BENVENISTE, 1995, p. 177).

A raiz indo-europeia da palavra "crença", para Benveniste, porta como significado a ideia de confiança, e mais, de forma obscura e enigmática, por derivações, porta o sentido de confiar seu próprio coração a alguém, como algo pessoal, uma força mágica que, nas palavras do autor, é colocada em um deus superior. Tem-se, portanto, o dar algo de si, o que no âmbito religioso é o se dar para um deus. O sujeito se dá aguardando uma recompensa, seja o reino dos céus, seja a resolução de um problema etc. Em Benveniste, o interessante é que essa ideia antiga de crença chega, nos dias de hoje, à de crédito... bancário! Embora, como ele próprio ressalte, o latim 'praestare' remetia para "colocar graciosamente à disposição, sem pensar em devolução e menos ainda em juros" (BENVENISTE, 1995, p. 179).

A partir da psicanálise, se seguimos as articulações que Kristeva (2007) elabora a partir desses traçados etimológicos de Benveniste, se a crença está na base da religiosidade, essa capacidade de acreditar no outro é anterior a qualquer forma de religião. Sendo constitutiva do sujeito, a confiança no outro é primeva, anterior à entrada na linguagem e, ao mesmo tempo, nos é constitutiva justamente porque somos falantes. Resulta dessa experiência de união entre mãe e bebê que institui no outro, "uma certeza, uma verdade última", de que pode ter confiança naquele que dele se ocupa. Isso tem a ver com o amor, com o que Freud vai chamar de sentimento oceânico, sentimento de união íntima no "corpo-a-corpo com a mãe. [...] uma certeza absoluta de satisfação e de segurança, mas ao mesmo tempo de perda de si. [...] é minha segurança, mas posso ser engolido"12. Aquele que dele se ocupa, por sua vez, aposta, mesmo sem o saber, que daquele corpo orgânico advirá um sujeito.

Logo, a crença, o crer, o confiar, não têm a ver com verdade ou mentira tal como a concebemos na cultura, na civilização. Tanto é assim que, para as crianças, o limite entre verdade e mentira não se dá de partida, é algo que vai sendo construído aos poucos pela família, pela escolarização e pelo sentimento religioso. ${ }^{13}$

12 Julia Kristeva, YouTube. Le besoin de croire
(https://www.youtube.com/watch?v=Q0x4p1NOMUE\&t=10s).

${ }^{13}$ São muitas as histórias, mas vale contar esta: uma menininha de 5 anos sempre dava corridas pela casa e ao passar por determinado local sempre derrubava um vaso. A mãe falou várias vezes para ela não correr por ali. Em dado momento, a mãe vê o vaso caído e reclama com a menina: "Filha, já te disse para não 
Ouvindo Kristeva ${ }^{14}$, ela diz que estamos vivendo um tempo de crise social, uma crise do sentido. Penso que muitas vezes nos enredamos nessas redes digitais, buscando crenças em meio às incertezas que vivemos. Crenças que se organizam nessa cola, nessa adesão a significantes identitários, sobretudo, quando enviados por grupos de sujeitos em quem confiamos.

\section{COMO OUVIR E LER?}

Em AD, trabalhamos com a historicidade, ou seja, com os movimentos do lembrar, do esquecer, do silenciar, do reiterar, do negar, do resistir (e tantos outros) que se inscrevem na materialidade dos processos de produção dos sentidos. Nos processos de produção de sentidos, se entendemos que esses processos não caminham em linha reta, pois produzem efeitos, há sempre mais de um sentido, ou melhor, no processo de produção está em jogo sempre mais de um sentido possível.

Assim, quando construímos nossos dispositivos de análise, visamos à compreensão de como os sentidos se constituem textualmente em relação às suas condições de produção e a outros sentidos possíveis ou silenciados. Enquanto analistas do discurso, nos posicionamos analiticamente nesse batimento entre descrição e interpretação, para observar e compreender os modos de textualização, de inscrição dos sentidos na materialidade da língua. Queremos compreender o processo de constituição dos sentidos, cujo funcionamento é parafrástico-polissêmico, como nos diz Orlandi (1996), sabendo que nesse processo e nesse funcionamento intervém a memória e joga o real, que, como instância impossível de ser dita, abre para o imprevisível.

Orlandi (1996) sempre precisa que esse funcionamento parafrástico-polissêmico da linguagem, inscrito na historicidade, guarda tensões: tensão resultante de uma repetição que pelo incessante retorno do mesmo pode desgastar e esvaziar a historicidade, produzindo um efeito papagaio ou robótico; tensão porque o real da história é constitutivo das margens da historicidade de qualquer processo de produção de sentidos, podendo fazer irromper não ditos inesperados, produzindo efeitos de fratura naquilo que é esperado; e uma repetição que, justamente por ser repetição inscrita em uma historicidade, pode deslizar para a produção de diferença, para a deriva nos processos de significação, produzindo efeitos de desestabilização e rupturas nas hegemonias ideológicas. Em suma, como Orlandi já nos disse tantas vezes, não há paráfrase sem polissemia, não há repetição sem diferença, não há o mesmo sem o outro. Os deslizamentos nas produções de sentidos são inerentes à ordem da língua porque a língua, objeto simbólico, é compreendida como sujeita a falhas.

Assim, toda discursividade prêt-à-porter pode se estilhaçar em farrapos a qualquer instante.

correr! Olha só, você derrubou o vaso!" E a menina responde de imediato: "Não fui eu, mamãe, foi ele!", e aponta para o irmãozinho de dois meses dormindo no berço.

14 Kristeva em Le Besoin de croire, no YouTube. Le besoin de croire (https://www.youtube.com/watch?v=Q0x4p1NOMUE\&t=10s). 


\section{REFERÊNCIAS}

BENVENISTE, E. O vocabulário das instituições indo-europeias. Vol. I. Campinas: Editora da Unicamp, 1995.

KRISTEVA, J. Cet incroyable nécéssité de croire. Paris: Bayard, 2007.

KRISTEVA. Le besoin de croire. Disponível em: https://www.youtube.com/watch? $\mathrm{v}=\mathrm{Q} 0 \mathrm{x} 4 \mathrm{p} 1 \mathrm{NOMUE} \& \mathrm{t}=10 \mathrm{~s}$. Consultas entre maio e junho de 2018.

LAGAZZI, S. O desafio de dizer não. Campinas: Pontes, 1988.

MARIANI, B. Sentidos de subjetividade: imprensa e psicanálise. Polifonia, vol. 12, núm. 1, Cuibá, Editora da UFMT, p. 21 a 45, 2006.

. O PCB e a imprensa. Rio de Janeiro; Campinas: Editora REVAN; Ed. da Unicamp, 1998. ORLANDI, E. Interpretação. Rio de Janeiro: Vozes, 1996.

. A linguagem e o seu funcionamento. São Paulo: Brasiliense, 1983.

PÊCHEUX, M.; GADET, F. [1981] A língua inatingível. O discurso na história da Linguística. Campinas: Pontes, 2004.

PÊCHEUX, M. [1982]. Discurso: estrutura ou acontecimento. Campinas: Pontes, 2011. . [1975]. Semântica e discurso. Uma crítica à afirmação do óbvio. Trad. Bras. Campinas: Ed. da Unicamp, 1988.

. [1969]. Análise automática do discurso. Em: GADET, F; HAK, T. Por uma análise automática do discurso. Campinas: Ed. da Unicamp, 1992.

RIVERA, T. A subversão do sujeito como gesto político. Psicanalistas pela democracia [Blog, texto postado em abril de 2017]. Disponível em: http://psicanalisedemocracia.com.br/2017/04/asubversao-do-sujeito-como-gesto-politico-por-tania-rivera/. Consultas entre maio e junho de 2018.

RODRIGUES, R.S. Posverdad y apocalipsis [texto inédito disponível no portal www.academia.edu, consultado em março de 2018]. Disponível em: https://www.academia.edu/36740082/POSVERDAD Y APOCALIPSIS1.

ROSSI LANDI, F. Il linguaggio come lavoro e come mercato: una teoria dela produzione e dell'allienazione linguistiche. Roma: Bonpiani, 1973.

Artigo recebido em: julho de 2018.

Aprovado e revisado em: novembro de 2018.

Publicado em: dezembro de 2018.

\section{Para citar este texto:}

MARIANI, Bethania. Discursividades prêt-à-porter, funcionamento de fake news e processos de identificação. Entremeios [Revista de Estudos do Discurso, ISSN 2179-3514, on-line, www.entremeios.inf.br], Seção Estudos, Programa de Pós-Graduação em Ciências da Linguagem (PPGCL), Universidade do Vale do Sapucaí (UNIVÁS), Pouso Alegre (MG), vol. 17, p. 3-18, jul. - dez. 2018.

DOI: http://dx.doi.org/10.20337/ISSN2179-3514revistaENTREMEIOSvol17pagina3a18 